\title{
A benchmarking study for reforming a Korean water department
}

\author{
S. Lee*, H. Park* and D. Choi ${ }^{\star *}$ \\ *Department of Civil and Environmental Eng, KAIST (Korea Advanced Institute of Science and Technology), \\ Daejon, 305-701, Korea (E-mail: hkpark@kaist.ac.kr) \\ ${ }^{\star \star}$ Nam Kyung Tech, Ansan, 425-110, Korea (E-mail: recycle@kaist.ac.kr)
}

\begin{abstract}
This study is aimed at developing internal reform plans for a water department of Seoul City by benchmarking it with selected best practices of the world. At first a performance indicator system was developed to logically evaluate concerns, problems, and issues of the Seoul water department. Since it is typical of Korean water services providers, the Seoul water department was selected while Tokyo's in Japan and Denver's in America were selected since they were considered as best practices of public waterworks much similar in governing structure to the one in Seoul. The results of benchmarking concluded that Seoul has traditionally been emphasizing more on "being a good public servant" providing drinking water services, and should be reformed in directions emphasizing 'entrepreneurship' to overcome its current limitations. Based on the results, a road map to reform the Seoul water department was established. Since it is typical in Korea, the reform plans and road map established were further recommended for reforming other drinking water services providers in Korea.
\end{abstract}

Keywords Drinking water service provider; benchmarking; performance indicator

\section{Introduction}

As summarized in Table 1, the Korean water industry is now facing many problems and many people agree that it needs to be reformed. In this regard, there are many discussions being undertaken among stakeholders. As it is pointed out these problems are due to the fact that most water businesses are owned and operated by local governments, a number of political solutions are under examination, which include combining local drinking water services providers (DWSP) and changing the existing ones into public water corporations, as well as privatization (Dongjin et al., 1999; Heekyung et al., 1997; Ministry of Environment, 2002; Seungcheon, 2001). But ultimate strategies won't be good solutions because ambitious attempts will not be able to overcome serious barriers, like opposition of corresponding officials, uneasiness of citizens, risks brought about in public services, and so on. Therefore reform plans inside organizations need to be developed effectively. This study suggests reforms by means of benchmarking with foreign DWSP which are operated by the public sector but achieve their purpose effectively (Alegre 2000; Bill et al., 1996; Howe et al., 2003; Heekyung et al., 2003; Larsson et al., 2002; Matos et al., 2002; TWUWS, 1996). These foreign DWSP were selected since, in our judgement, their governing structures were similar to our providers'. If we could find and verify some of their good points, the similar structures make it much easier for us to accommodate them into the Korean situation.

\section{Methods}

\section{Selection of a sample and best practices}

As a sample for analysis of Korean DWSP, the Office of Waterworks belonging to Seoul Metropolitan Government was selected. It provides a population of more than 10 millions in Seoul with complete water service from uptake of raw water to distribution of treated 
Table 1 Major problems of Korean water industry

\begin{tabular}{ll}
\hline & Major problems \\
\hline Political institutional setups & $\begin{array}{l}\text { Government's policy for supply } \\
\text { Installer's direct control on the water supply system } \\
\text { Regional unbalance owing to operation by an administrative district } \\
\text { Lack of reality of the long-term plan }\end{array}$ \\
Personnel & Lablems to adopt professional management \\
& Insufficient incentives for a competitive spirit between employees \\
& Facility deterioration and experimental equipment shortage \\
L \& M & Low cost recovery rate \\
& Cost structure not considering economic principles \\
Finance & Increasing debts \\
Customer relationship & Customer's lack of confidence in the water service \\
& Inactivity of public information for reliance uplift \\
\hline
\end{tabular}

water, and is considered to be the greatest and supreme in Korea. It could also be regarded as a typical DWSP since every DWSP in Korea has operated on the same basis, including organizational composition, personnel system, facility operation, management principles, financial method, tariff system and so on, though adopting 'self-supporting accounting system'. Similarly, it has suffered from the same problems, presented in Table 1.

To select objects of comparison, best practices, Seoul's characteristics and its political concerns were analyzed first. Comparison with the object satisfying the former and being the paragon of the latter can provide realistic means for the solution of its concerns. Although we could point out a similar provider (the Bureau of Waterworks which belongs to Tokyo Metropolitan Government) through lots of investigation, it would be difficult to say that Tokyo's DWSP is a paragon. So to speak, it also encounters the same problems according to its similar system. Therefore another object (Denver Water) was selected additionally, which is largely operated by the public sector but considered to be an efficient and effective provider.

Development of performance indicator system (PIS)

For PIS development, the following were taken into account.

(1) Development process of PIS should reflect on business goals, existing problems and latest issues of DWSP.

(2) PIS should represent all the relevant aspects of performances of DWSP.

(3) PIS should allow for a comprehensive representation of the system by a reduced number of PIS.

(4) PIS should assess efficiency and effectiveness of DWSP.

(5) PIS should be clearly defined and its data should be easily accessible.

(6) PIS should be selected to be as quantitative as possible with the exception of cases to explain large differences in each structure.

Specially, to satisfy condition 1, the process in Figure 1 was developed. It is logical to make many concerns reflecting to PIS. The logical process also gave merits to reduce the number of indicators, constraining the boundary of PIS in need.

\section{Computation of performance values among 3 DWSP}

The Performance Indicators finally selected are presented in Table 2. The system is first classified into two groups, Publicity and Entrepreneurship, and then a number of sub-groups. "Publicity" is an indicator to measure the degree of effectiveness by which the water departments provide public services as a government agency, and "Entrepreneurship" is to 
STEP1) Preparation of comprehensive performance indicators

\begin{tabular}{|c|c|c|c|c|c|c|}
\hline Indicator & $\begin{array}{l}\text { Personnel } \\
\text { Indicators }\end{array}$ & $\begin{array}{l}\text { Ptpribar } \\
\text { Indicators }\end{array}$ & $\begin{array}{l}\text { Operational } \\
\text { Indicators }\end{array}$ & $\begin{array}{l}\text { Onfiny of } \\
\text { Benvice inatcator }\end{array}$ & $\begin{array}{l}\text { Fmanciel } \\
\text { Indicators }\end{array}$ & $\begin{array}{l}\text { Publechy } \\
\text { Puacmion }\end{array}$ \\
\hline $\begin{array}{l}\text { Mumber of } \\
\text { Indicatork }\end{array}$ & 20 & 75 & 39 & 20 & 33 & 13 \\
\hline
\end{tabular}

(Totul unnerer : 140

STEP2) Division of business goals

Publicity

Safe Supply of Clean Water

Improvem ent of supply coverage \& water quality, Security of water resource, Expansion of facilitie

Entreprenauship Pusuit of Efficiency in Operafio

Water savings, Control of demand, Cost recovery, Decrease of NRW, Employment of competent staff

STEP3) Selection of requisites according to above business goals

$\square$ In case of Publicity

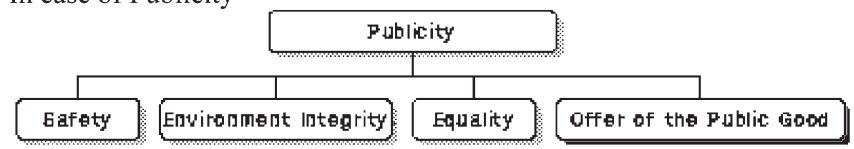

$\square$ In case of Entrepreneurship

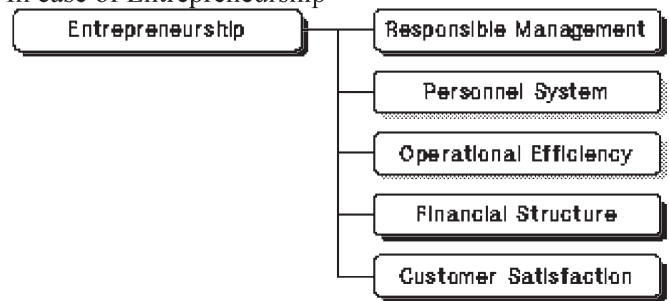

STEP4) Linkage of above requisites with keynotes including important matters, uncovered problems and social issues

For example,

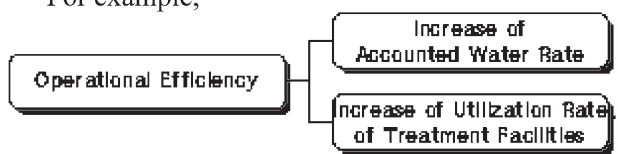

STEP5) Selection or modification of prepared performance indicators, fitting to each keynote

Figure 1 Development process of performance indicator system

measure the degree of efficiency as an entrepreneur. Some performance indicators were modified qualitatively to prevent wrong analysis due to dissimilarity of the three DWSP. In some cases, moreover, using qualitative indicators was more effective and analytical. So, the evaluating method was divided into qualitative and quantitative. Consequently, additional ranks were used to evaluate on an equal base with respect to 2 types of indicators in this study, so that relative performance values were computed against each other. They made requisites for the business goals like 'Safety' or, 'Environment Integrity' contrary to development process of PIS. Therefore, "the relative performance value of a requisite is 100 " means all values of performance indicators in that requisite are best among 3 DWSP.

\section{Result and discussion}

\section{Result analysis}

To compare to what extent the three DWSP satisfied their business goals, Figure 2 shows them in a graphical form using performance values of requisites according to business goals. This graph convinced us of some conclusions. 
Table 2 Performance indicators selected finally

\begin{tabular}{|c|c|c|c|c|c|c|}
\hline \multirow{2}{*}{$\begin{array}{l}\text { Performance indicator } \\
\text { Resource security }\end{array}$} & \multicolumn{3}{|c|}{ Rank } & \multicolumn{3}{|c|}{ Performance value } \\
\hline & 1 & 2 & 3 & 50 & 33.3 & 16.7 \\
\hline Response system against the emergency or drought & 2 & 1 & 3 & 33.3 & 50 & 33.3 \\
\hline Safety & & & & 83.3 & 83.3 & 50 \\
\hline Water quality standard & 3 & 1 & 1 & 16.7 & 25 & 16.7 \\
\hline Standard satisfaction & 1 & 1 & 1 & 25 & 25 & 25 \\
\hline Current status of water source management & 3 & 1 & 1 & 8.3 & 25 & 25 \\
\hline Pollution level of water source & 3 & 2 & 1 & 16.7 & 8.3 & 25 \\
\hline Environment integrity & & & & 66.7 & 83.3 & 91.7 \\
\hline Service coverage & 1 & 1 & 1 & 50 & 50 & 50 \\
\hline Tariff system concerned with the low-income group & 2 & 1 & 3 & 33.3 & 50 & 16.7 \\
\hline Equity & & & & 83.3 & 100 & 66.7 \\
\hline Master-plan of the water system & 1 & 1 & 3 & 50 & 50 & 16.7 \\
\hline Form/action of customer protection organization & 3 & 1 & 1 & 8.3 & 25 & 25 \\
\hline Services for the citizen except the water supply & 3 & 1 & 1 & 8.3 & 25 & 25 \\
\hline Offer of public benefit & & & & 66.6 & 100 & 66.7 \\
\hline Supreme decision-maker & 2 & 2 & 1 & 33.3 & 33.3 & 50 \\
\hline Dependency on local government & 2 & 2 & 1 & 33.3 & 33.3 & 50 \\
\hline Responsible management & & & & 66.6 & 66.6 & 100 \\
\hline Population served per employee & 1 & 2 & 3 & 25 & 16.7 & 8.3 \\
\hline Recruitment system & 3 & 2 & 1 & 8.3 & 16.7 & 25 \\
\hline Percentage of full time equivalent employees & 3 & 2 & 1 & 4.2 & 8.3 & 12.5 \\
\hline Training program & 3 & 1 & 2 & 4.2 & 12.5 & 8.3 \\
\hline Incentive institution & 3 & 1 & 1 & 8.3 & 25 & 25 \\
\hline Personnel system & & & & 50 & 79.2 & 79.1 \\
\hline Pipe failures & 3 & 2 & 1 & 5.6 & 11.1 & 16.7 \\
\hline Non-revenue water & 3 & 2 & 1 & 5.6 & 11.1 & 16.7 \\
\hline Mains rehabilitation & 3 & 2 & 1 & 5.6 & 11.1 & 16.7 \\
\hline Treatment utilization & 3 & 1 & 1 & 16.7 & 50 & 50 \\
\hline Operational efficiency & & & & 33.5 & 83.3 & 100 \\
\hline Average tariff by GDP & 3 & 2 & 1 & 16.7 & 33.3 & 50 \\
\hline Working ratio & 3 & 2 & 1 & 5.6 & 11.1 & 16.7 \\
\hline Annual cost of investments & 2 & 3 & 1 & 11.1 & 5.6 & 16.7 \\
\hline Debt ratio & 2 & 1 & 3 & 11.1 & 16.7 & 5.6 \\
\hline Financial structure & & & & 44.5 & 66.7 & 89 \\
\hline Drinking ratio & 3 & 2 & 1 & 16.7 & 33.3 & 50 \\
\hline Service satisfaction & 3 & 2 & 1 & 16.7 & 33.3 & 50 \\
\hline Customer satisfaction & & & & 33.4 & 66.6 & 100 \\
\hline
\end{tabular}

(1) Seoul's DWSP is poor at both 'Publicity' and 'Entrepreneurship'.

(2) There is more room for improvement in 'Entrepreneurship' than 'Publicity'.

(3) Tokyo's DWSP is distinguished in 'Publicity', yet Denver's is excellent in 'Entrepreneurship'.

(4) For 'Publicity' model, Tokyo's should be selected.

(5) For 'Entrepreneurship' model, Denver's should be selected.

Besides, Tokyo's DWSP is similar to Seoul's and also resembles its graph shape in Publicity. It seems that there is no concern between two DWSP in Entrepreneurship, because Tokyo's is thought to invest boldly in facilities, pipe repairs or replacement, expansion of professional staff according to its long-term master-plan with abundant fund of local government. But if the fact that Tokyo DWSP has uncovered serious problems about profitability is taken into account, Seoul's would have to make the existing system efficient rather than get the counter-plan to gather funds.

Criterion development for application of obtained reform plans

A number of reform plans were obtained consecutively from process benchmarking and system comparison (strengths and weaknesses comparison with best practices). Plans were adjusted in the form presented in Table 3. 


\section{PUBLICITY}
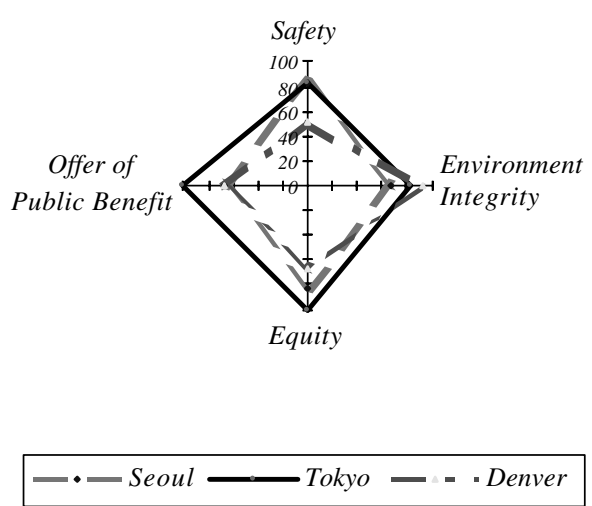

\section{ENTREPRENEURSHIP}

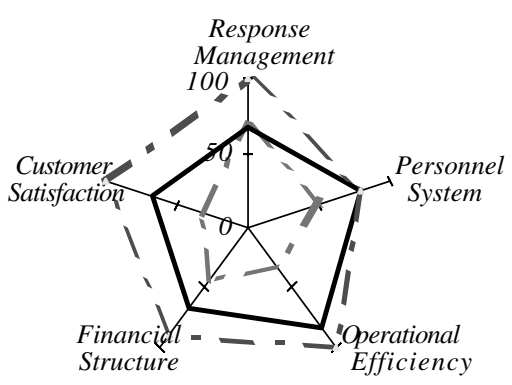

- - -Seoul Tokyo - - - Denver

Figure 2 Performance values comparison according to business goals

Although reform plans are needed to improve DWSP in Korea, without exception, application of all plans simultaneously could confuse an organization. Moreover, it would burden its own local government with large funds to invest. Therefore it was necessary to develop a series of criteria help to determine the priority order. The developed criteria are as follows.

(1) Is promotion of the reform plan urgent because its performance values are much lower than best practices?

(2) Could it be applied at the current level?

(3) Is it indispensable to promote other plans later?

Table 3 Reform plans about operational efficiency adjusted to the ordered form

\begin{tabular}{|c|c|c|c|c|}
\hline & Reform plan & Direction & Ref. & Performance indicator \\
\hline \multirow[t]{2}{*}{$\begin{array}{l}\text { Operational } \\
\text { efficiency }\end{array}$} & $\begin{array}{l}\text { Innovative reparation of } \\
\text { distribution facilities }\end{array}$ & $\begin{array}{l}\text { Promotion of large pipe } \\
\text { repair work under } \\
\text { powerful long-term plan }\end{array}$ & Tokyo & $\begin{array}{l}\text { Leakage rate, } \\
\text { leakage control, integrity } \\
\text { of distribution facility }\end{array}$ \\
\hline & $\begin{array}{l}\text { Improvement of } \\
\text { operation rate }\end{array}$ & $\begin{array}{l}\text { Promotion of integration } \\
\text { or control between } \\
\text { treatment facilities }\end{array}$ & Denver & $\begin{array}{l}\text { Utilization rate of water, } \\
\text { treatment facility }\end{array}$ \\
\hline
\end{tabular}




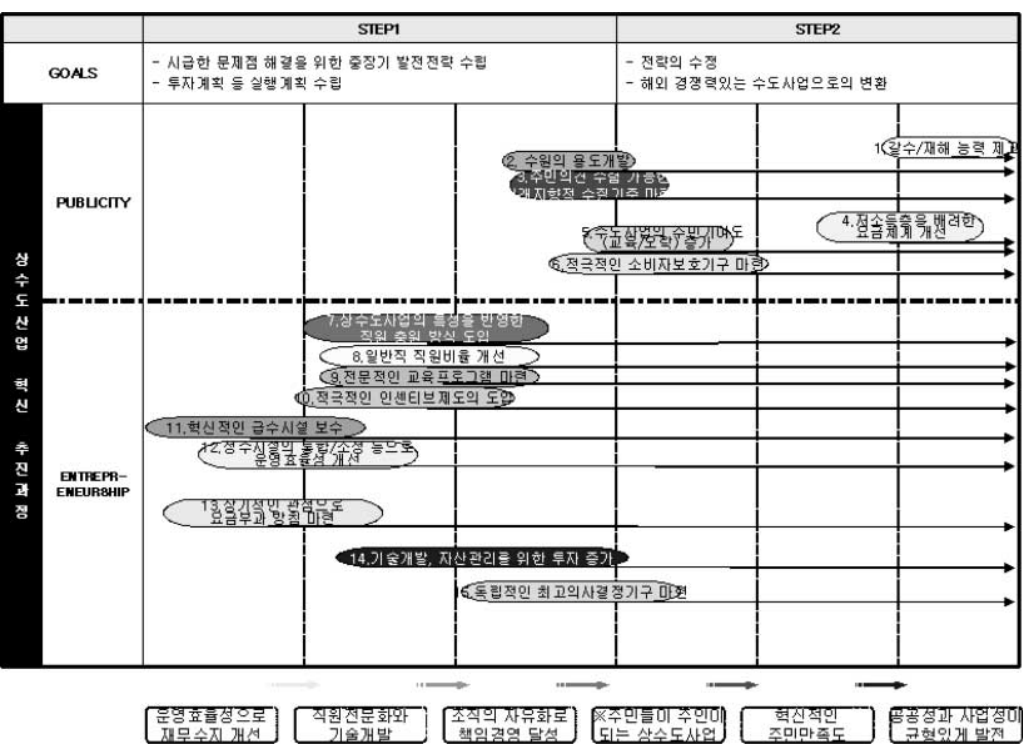

Figure 3 Obtained road map (written in the Korean language)

\section{Installation of a road map}

According to above criterion, a road map for improvement of DWSP in Korea was drawn, in Figures 3 and 4. Application process was divided into 3 steps on the milestone. (1) STEP 1 ('Catch-up' process)

Business goal of DWSP has not reached levels of best practices of Tokyo and Denver, but advancing to well balanced development in both Publicity and Entrepreneurship. So 'catch-up' process also means to lift up appropriate level enough to develop them in well balanced manner. In case of Korean DWSP, reform plans for Entrepreneurship should be emphasized more.

(2) STEP 2 ('Balanced Development' process)

Second step is promoting plans to develop them in a well balanced manner. Taking aim at Publicity superior to Tokyo and Entrepreneurship superior to Denver, they should apply reform plans for both of them in decisive terms with fixing plans at first step successfully.

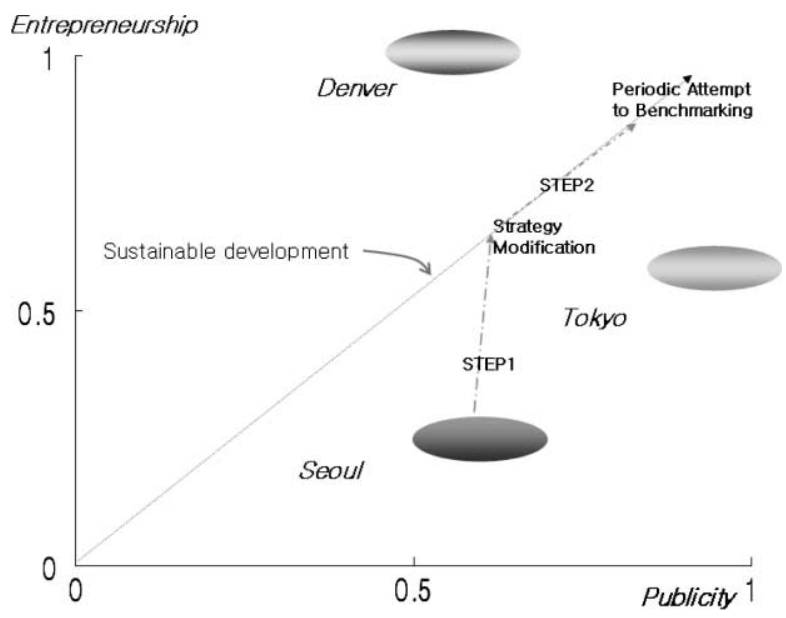

Figure 4 Milestone for sustainable development 
(3) STEP 3 ('Periodic Attempt to Benchmarking' process)

To advance DWSP sustainably, a periodic benchmarking with identical best practices is inevitable. It would provide DWSP with the opportunity to evaluate the attainment of promoted plans. It would also complete the new scheme with the course of best practices.

\section{Conclusions}

This study has 2 significant aspects. Reform plans obtained by benchmarking can first make the management team improve performances of its organization. Even if self-supporting accounting system is adopted the actual operation of the Korean DWSP would still be dependent on directions of the central and the local governments. Before promoting these reform plans the need to change should be notified to decision-makers. To verify need to change Korean DWSP, this study was used to do benchmarking with excellent DWSP in developed countries so that we can convince them that changes must be undertaken without delay.

Any benchmarking tool has not been applied to the water industry in Korea until now. If this tool is polished to further perfection, it can make Korean DWSP more competent.

\section{References}

Alegre, H. (2000). Performance Indicators for Water Supply Services. IWA Publishing, London, UK.

Dongjin, C. et al. (1999). Privatization of Water Industry in a Developing Country. Japan Water Works Association.

Heekyung, P. et al. (2003). Analysis of the Water System in America \& Japan, Korea Water and Wastewater Works Association.

Heekyung, P. et al. (1997). A Conceptual Review of a 21st Century Management System for the Waters in Korea, American Water Works Association.

Howe, C. W. et al. (2003). Privatization of Water Services in the United States. Committee on Privatization of Water Services in the United States.

Kingdom, B. et al. (1996). Performance Benchmarking for Water Utilities. AWWARF and AWWA.

Larsson, M. et al. (2002). Process Benchmarking in the Water Industry. IWA Publishing, London, UK.

Ministry of Environment (2002). 2001 Statistics for Drinking Water (in Korean).

Matos, R. et al. (2002). Performance Indicators for Wastewater Services, IWA Publishing, London, UK.

Seungcheon, B. et al. (2001). Development plans for local water businesses, Korea local-government

Management Institute (in Korean).

TWUWS (1996). Indicators: Water and Wastewater Utilities (2nd Edition). World Bank, Washington DC, USA. 